\title{
Derechos humanos y derechos lingüísticos indígenas de Colombia
}

\author{
Human Rights and Indigenous Linguistic Rights of Colombia
}

\author{
Yuri Elena Oliveros Marín \\ Magister en Derechos Humanos. \\ Secretaría de Cultura, Recreación y Deporte de Bogotá, Colombia. \\ oliverosmarinye@gmail.com (i) https://orcid.org/0000-0002-8498-5059
}

Fecha de recepción: 29 de marzo de 2016

Fecha de aprobación: 17 de mayo de 2017

Cómo citar este artículo/ to reference this article

Oliveros Marín, Y. (2017). Derechos humanos y derechos lingüísticos indígenas de Colombia. Derecho Y Realidad, 15(29): e6128. Recuperado a partir de https://revistas.uptc.edu.co/index.php/derecho_realidad/article/view/6128

Resumen: el propósito del artículo es aportar al debate de los derechos humanos un acercamiento a la relación de estos con los derechos lingüísticos en los pueblos indígenas, a partir de la pregunta: ¿Cuál es la relación entre derechos humanos y derechos lingüísticos en los pueblos indígenas de Colombia? El diseño metodológico para el proyecto toma, desde la antropología, el método etnográfico, que ha sido utilizado por la disciplina para estudiar la manera en que las normas, las ideas y los discursos de derechos humanos son abordados por los actores sociales. Se evidencia que es necesario incorporar un diálogo de saberes intercultural al debate. Se concluye que, si bien, la lengua nativa es parte esencial al definir a un pueblo indígena, por situaciones históricas no todos los pueblos han conservado su lengua, aun así deben ejercer su derecho a defenderla.

Palabras clave: derechos lingüísticos, derechos humanos, justicia transicional, pueblos indígenas, sujeto de derechos humanos.

\begin{abstract}
The purpose of the article is to contribute to the debate on human rights an approach to their relationship with linguistic rights in the indigenous peoples, based on the question: What is the relationship between human rights and linguistic rights in the villages? indigenous people of Colombia? The methodological design for the project takes, from anthropology, the ethnographic method, which has been used by the discipline to study the way in which norms, ideas and human rights discourses are addressed by social actors. It is evident that it is necessary to incorporate an intercultural knowledge dialogue into the debate. It is concluded that, although the native language is an essential part in defining an
\end{abstract}


indigenous people, by historical situations not all peoples have retained their language, yet they must exercise their right to defend it.

Keywords: linguistic rights, human rights, transitional justice, indigenous people, subject of human rights.

\section{Introducción}

Este artículo está basado en el proyecto de investigación de Maestría en Derechos Humanos: "Ecos de lenguas nativas y voces de lucha". El diseño metodológico para el proyecto toma, desde la antropología, el método etnográfico, que ha sido utilizado por esta disciplina para estudiar la manera en que las normas, las ideas y los discursos de derechos humanos son entendidos, apropiados, negociados, significados y resignificados o constituidos en la práctica por diferentes actores sociales. Se privilegia a los actores y sus comunidades, posibilita la valoración de cómo los derechos humanos son socialmente constituidos en la práctica, más allá del análisis institucional, normativo y discursivo. Además, pone énfasis en la multiplicidad de ángulos de lectura de estos, motivando así los diálogos interculturales, lo cual se hace cada vez más urgente.

Por lo tanto, se parte de una de las características del concepto de derechos humanos de Maquieira (2006), como proceso inacabado en un espacio y tiempo específicos; los derechos humanos se conciben como un concepto en construcción permanente, dialéctico y sujeto al contexto. Por otro lado, los derechos lingüísticos son todos los que se relacionan con la lengua propia, pero, al mismo tiempo, con derechos fundamentales cuya garantía depende del respeto por la lengua.

Este artículo plantea desde la imperativa reconceptualización de derechos humanos, teniendo en cuenta su integralidad y una perspectiva crítica en las lecturas de las realidades y de las otredades, siendo fieles al contexto y al momento histórico de su construcción. Dado el vaciamiento teórico-práctico del concepto, su situación hoy en Colombia no es muy alentadora. El vaciamiento de sentido de este se debe en gran parte a la banalización del término (Restrepo, 2006).

El propósito de la investigación realizada es aportar al debate de los derechos humanos un acercamiento a la relación de estos con los derechos lingüísticos en los pueblos indígenas de Colombia, teniendo en cuenta que al revisar el estado del tema de los derechos lingüísticos no se dilucidan de manera clara elementos de la lengua como instrumento de dominación o herramienta de control en las relaciones de poder donde el sistema es excluyente, por lo cual hay una carencia en la realidad conceptual en la que se debe fundamentar. Asimismo, es necesario incorporar un diálogo de saberes intercultural al debate.

Los pueblos han enfrentado históricamente opresiones, incluidas las lingüísticas. Estas constantes agresiones y avasallamientos han sido una herramienta fuerte de dominación, atravesada por relaciones de poder inherentes a las acciones unificadoras, "civilizadoras" o de "salvación". Esa dominación se ha perpetuado en la psiquis de la población, como resultado del carácter desigual que tuvo la llamada "conquista de América", y que desde la colonia, pasando por la república, se fue profundizando. Aún seguimos viendo los resultados de esto, quizá porque todavía no tenemos un proyecto de nación conjunta que incluya a todos los grupos étnicos. 
Este texto inicia con una breve contextualización de los pueblos indígenas, que abre paso al estado del tema de los derechos lingüísticos y a un marco teórico de los derechos humanos, principalmente desde América Latina. Seguidamente se concentra en una caracterización de la relación entre modernidad y derechos humanos, para describir la influencia de este periodo sobre los pueblos indígenas de Colombia. Luego avanza en la conceptualización de sujeto de derechos humanos y desarrolla el concepto con argumentos de hechos históricos o contextualizados en Colombia desde las acciones y la capacidad de reconocerse en los otros más allá de lo jurídico para luchar por sus derechos. Posteriormente desarrolla la categoría de derechos lingüísticos y, en último término muestra un resumen con análisis del marco legal, el cual contiene insumos para la exigibilidad de los derechos lingüísticos; se contrasta el derecho propio indígena en sus principios con el derecho estatal, y se presenta una reflexión sobre la justicia transicional, así como unas conclusiones generales.

\section{Antecedentes y estado de la cuestión}

Las disciplinas en las que se discute sobre derechos lingüísticos han sido, tradicionalmente, la sociolingüística, la sociología de la lengua, la lingüística aplicada, y la política de la lengua; posteriormente se añaden la antropología jurídica, la teoría política y la legislación internacional.

Al realizar la búsqueda, la revisión bibliográfica del estado del tema de los estudios existentes relacionados con la pregunta, muestra una falta de formulación teórica sobre la relación entre derechos lingüísticos $\mathrm{y}$ derechos humanos en pueblos indígenas que responda a la investigación. Sin embargo, encontramos elementos por separado en varios trabajos tanto en el ámbito nacional como internacional. En ambos ámbitos se soslaya la acción de los sujetos políticos frente a la problemática.

Buscando una ruptura del eurocentrismo en la episteme, se consultaron autores que trabajan desde el pensamiento latinoamericano más allá de la nacionalidad, es la manera en que construye las ideas respecto a lo "culto" y lo salvaje o primitivo del pensamiento del sur. En lo pedagógico es donde encontramos más trabajos que relacionan las lenguas indígenas con sus luchas. Se encuentra principalmente trabajado el tema de la etnoeducación y de la educación intercultural bilingüe, desde la caracterización de determinados pueblos o estudios comparados, como es el caso de la tesis "Educación intercultural bilingüe (EIB), una visión comparada entre Ecuador y Bolivia", de Lovich (2010).

Hay un creciente interés desde hace veinte años por los derechos lingüísticos y su fundamentación teórica teniendo en cuenta diversas disciplinas. La categoría de los derechos lingüísticos es un tema novedoso y complejo. Lo que reflejan los estudios es el imperativo uso de un enfoque cada vez más interdisciplinario que nutra la compleja conceptualización de un tema que, en su construcción, como todos los derechos humanos, está en constante movimiento. Dentro de las disciplinas encontramos la antropología, la psicología, la sociolinguística, la historia y la filosofía política.

Por otro lado, se ha desarrollado en torno a las políticas lingüísticas el libro El derecho a la lengua: una historia de la política lingüística en Colombia, de Pineda (2000), donde se hace un recuento histórico y un análisis de las políticas lingüísticas en Colombia desde la época de la conquista hasta el año 2000. El autor no escatima en la descripción de las transformaciones 
o propuestas nuevas en el contexto colombiano, sino que alimenta su texto con ejemplos en el contexto europeo, canadiense y de otros países de Latinoamérica, como Bolivia, México y Perú. Posterior a ese año, en el contexto colombiano se han escrito artículos desde el ángulo de lo político-jurídico, tales como "La diversidad lingüística en Colombia: protección jurídica de las lenguas indígenas" (Rojas, 2013), o "Las lenguas autóctonas en Colombia: consideraciones alrededor de su legitimación en la Constitución de 1991", a cargo de Daniel Aguirre Licht (2009), quien compila a las autoras Ilse Gröll, María Emilia Montes Rodríguez y Ruth Pappenheim Murcia.

Son Skutnabb-Kangas y Phillipson (1994) quienes introducen el término de derecho humano lingüístico; sin embargo, su argumentación está planteada de tal manera que no cuestiona a los grupos minoritarios y sus dinámicas o a los miembros de estos. Es decir, presupone que estos asumen, sí o sí, su identidad, y que no hay conflictos.

Stephen May (2011) es quizás el autor que ha cuestionado las tendencias ecologista y la de derecho humano lingüístico. Él propone una argumentación interdisciplinar y tiene en cuenta la diferenciación entre comunidad o colectivo e individuo que no necesariamente quiere asumir el rol de miembro de estos grupos lingüísticos. No obstante, no encontramos ningún autor que trabaje las estrategias e iniciativas desde los sujetos empoderados. Aunque entendemos de alguna manera tal perspectiva, considerando que es en América Latina donde hay diversas manifestaciones contrahegemónicas. Por tal razón, este estudio, realizado desde América latina, tiene la responsabilidad de aportar a la sistematización estrategias y debilidades desde la organización indígena; un contexto, por decirlo así, único, en las movilizaciones, resistencias y luchas políticas.

En el mapa de los países que ratificaron el Convenio 169 de la OIT, la gran mayoría está en América Latina, lo cual vislumbra las dinámicas de movilización e intereses en el mundo. Una región que se moviliza a favor de los derechos de las minorías a pesar de tener una historia de dictaduras opresivas.

Desde el ángulo antropológico colombiano, Marta Pavón (1995) hace una compilación de trabajos bajo el título La recuperación de lenguas nativas como búsqueda de la identidad étnica. El antropólogo Roberto Pineda Camacho (2000) hace un trabajo exhaustivo sobre el derecho a la lengua y la historia de las políticas lingüísticas para las lenguas nativas, que muestra los alcances y limitaciones por parte de la institucionalidad, no siendo así sobre el rol de las luchas o reivindicaciones de los pueblos y sus iniciativas. Desde esta disciplina, en el contexto colombiano se cuenta también con estudios sobre las lenguas indígenas en el Nuevo Reino de Granada y posteriormente. Además, con la obra descriptiva más completa desde el trabajo de un grupo de investigadores.

Es interesante la producción desde las iniciativas indígenas, por ejemplo, el artículo de Green (2006), "La educación desde la Madre Tierra: un compromiso con la humanidad", del proyecto de investigación: "La lucha de los siete hermanos y su hermana Olowaili en defensa de la Madre Tierra: hacia la pervivencia cultural del pueblo Tule".

En los trabajos consultados no se dilucidan de manera clara elementos de la lengua como instrumento de dominación o herramienta de control en las relaciones de poder. La lengua materna juega un papel crucial en la resistencia, el giro decolonial, en unas relaciones de poder donde el sistema es excluyente, por lo cual hay una carencia en la realidad conceptual 
en la que se debe fundamentar. Asimismo, es importante incorporar un diálogo de saberes intercultural al debate.

En las realidades observadas y los textos revisados existe un vacío en las explicaciones acerca de la relación entre derechos humanos y derechos lingüísticos. Además de la pobre sistematización de estrategias "desde abajo", es decir, desde las bases por parte del movimiento indígena.

\subsection{Derechos humanos}

"La teoría sólo tiene sentido en la medida en que luchamos por la vida" (Nikos Poulantzas, 1978)

Los derechos humanos esencialmente son históricos, contextuales y resultado de procesos de luchas colectivas. Además tienen cuatro dimensiones: ética, social, política, y jurídica. En relación con su dimensión ética, se centran en la expresión de la dignidad. En cuanto a lo político, se derivan y se hacen efectivos desde la justicia, partiendo de los principios de igualdad y libertad. Respecto a su dimensión social, vislumbran la solidaridad expresada en las luchas colectivas de los pueblos en contra de la represión, dominación y explotación, convirtiendo así a los derechos humanos en símbolos de emancipación. Sobre lo jurídico, definen prácticas políticas específicas y propician la regulación garantizando su cumplimiento; por ello, las políticas públicas suficientes y eficaces son un instrumento que posibilita su accionar, aunque no el único.

Para construir el concepto de derechos humanos desde la teoría crítica, se considera la integralidad de los seres humanos y su dignidad, pues la segunda es la esencia de estos, la palabra clave. Pensemos en derechos humanos privados y deshumanizados. ¿Cómo humanizar y devolverle la vitalidad al concepto? El rol de humanizarlos y de darles vida lo tiene la sociedad civil movilizada en el poder del ahora. Cuando hablamos del ahora nos referimos al momento histórico que se construye de cotidianidades periféricas, en sus subjetividades de resistencias.

El concepto es claramente controversial, su historia lo demuestra. En el contexto colombiano hay un vaciamiento y una pérdida del significado que amerita la reconceptualización. De igual modo, las políticas de derechos humanos están influenciadas por su teoría implícita, y el descuido de la teoría llevará a un inadecuado entendimiento de las políticas, así como a una justificación de la práctica.

Los derechos humanos son una categoría que necesita aire, es decir, requieren una nueva conceptualización que los empodere en su esencia de las luchas por la dignidad humana y fortalezcan la intención del discurso de estos para su exigibilidad. El pulso de la categoría parece agonizante en un mundo de licuefacción (Bauman, 1999). Dado el vaciamiento del concepto, se requiere una reconstrucción constante y perpetua en la cotidianidad del ejercicio, que le devuelva la voz al concepto de derechos humanos, y que estos, a su vez, sean entendidos como luchas ejecutadas por la sociedad civil en las relaciones de poder que configuran y definen una realidad que hace visibles a los sujetos que emprenden el camino por ejercer el poder en pro de una dignidad. Para la comprensión de los fundamentos de los derechos humanos debe considerarse que ellos surgieron en el desarrollo de procesos históricos marcados por hechos de indignación e inconformidad ante la desigualdad y el 
desequilibrio social generados en la Edad Moderna, bajo la idea del capital. En el nacimiento y desarrollo de un nuevo modo de producción, el capital viola la integridad de la vida del ser humano y prevalece entonces la idea de una concepción individualista en la sociedad.

Los derechos humanos pueden ser tomados entonces como un indicador de progreso histórico de la humanidad, en cuanto son producto de las luchas sociales sobre la base de la realización efectiva de la dignidad humana, en la dinámica de unos contextos sociales, políticos y económicos que generan orden, como una respuesta que da el ser humano ante los entornos naturales y contextos específicos que tiene que vivir; las relaciones humanas que se desarrollan en la cotidianidad en el interior de los diferentes sistemas, lo cual conlleva unas transformaciones, adaptaciones y producción de derechos en contextos situados, históricos y concretos, ligados al empoderamiento de los sujetos, a la defensa de sus necesidades. Se desarrollan en un tiempo y espacialidad en la que los individuos exigen y procuran por sus necesidades y por sus pensamientos e ideales. Teniendo en cuenta lo anterior, los derechos humanos representan la realidad en la que se vive, y se dan en un proceso de pensamiento complejo, ecléctico, en el que se pretende la reivindicación del ser humano.

Dilucidan la felicidad de la guerra, es decir, una fiesta de la unión, de la unificación del pensamiento que controla y quiere poner orden, que combate la pluralidad. La cual es la promoción de las diferencias como único territorio posible del pensamiento. Además, aluden al ser humano en medio de un nudo de relaciones e intercambios en una lucha inacabada, pues existe la necesidad de una comunicación humana respetuosa como fundamento de la paz, que no es igual a sumisión, obediencia o terror que controle (Restrepo, 2006). En resumen, los derechos humanos hoy están asociados o presentes en todos los campos y dimensiones en los que se toman decisiones sobre la vida política, social y cultural de una nación.

\subsection{Derechos humanos y modernidad}

Una de las características principales de la modernidad en Occidente es la industrialización, la aparición de la fábrica y la automatización del trabajo. Es la máquina la que llega a imponerse en la producción en masa, en serie, a remplazar lo artesanal o a reforzar la mano de obra humana. Es también el paso de lo rural a lo urbano.

Se hace necesario abordar la modernidad para reflexionar sobre los derechos humanos, pues en este periodo se empiezan a consolidar el concepto y la conciencia social y política sobre los derechos humanos, que también contribuyeron al afianzamiento de la cultura moderna (Angarita, 2000).

El paradigma de la modernidad se hilvana apoyado en la promesa de equilibrio entre el pilar de la regulación y de la emancipación (De Sousa Santos, 1998). Sin embargo, en este camino que se hace al andar, hay un aumento en el déficit y una disminución en su capacidad de cumplir las promesas que basculan entre estos dos pilares, donde el de la regulación tiende a dominar, creando a través de su maximización una relación de poder sin armonía y desbalanceada y dejando debilitado el pilar de la emancipación.

Es así como el proyecto de la modernidad que nace con promesas de equilibrio se traduce en la frustración de lo no cumplido, puesto que las fuerzas abstractas de cada pilar tienden a maximizarse a ritmos distintos y en su interior, repitiéndose este fenómeno por la independencia y funcionalidad diferenciada de cada principio. Específicamente, en el pilar de 
la regulación encontramos el principio de Estado, el de mercado y de comunidad; en contraste, el pilar de la emancipación tiene en su interior las racionalidades: estéticaexpresiva, cognitiva-instrumental y práctica-moral.

Luego, el pilar dominante y hegemónico en la modernidad es el pilar de la regulación y particularmente el principio del mercado, vertido sobre el Estado y la comunidad. Así, los mercados están más expandidos, fuertes, irresponsables; los Estados son más autoritarios, militarizados y con menos compromiso social; los individuos son transformados en clientes y concentrados en su microética. No obstante, las mutaciones en el pilar de la emancipación son fundamentales para entender el paradigma de la posmodernidad, el cual empieza en el cambio de las racionalidades. Es decir, surgen las microrracionalidades y las microrrevoluciones.

Por otro lado, el rol del lenguaje va variando. En la premodernidad, es sobre todo oral en general. Posteriormente, en la modernidad, predomina la lengua escrita. Encontramos en el contexto colombiano los juglares y los pueblos indígenas, los cuales se han caracterizado por su oralidad. Esta carencia de lengua escrita les ha costado hasta este momento histórico una discriminación e incluso a sus lenguas se les ha llamado dialecto primitivo, no civilizado. Luego aparece el lenguaje virtual, del cual se van a servir los movimientos sociales para su movilización, creación de redes y visibilización de las luchas.

La promesa de la modernidad o un Estado con más poder e incidencia en la calidad de vida de los sujetos ha sido incumplida. Queda demostrado extensamente en los objetivos no cumplidos, la falta de voluntad política y la situación actual de los pueblos indígenas. Hay que resaltar el trabajo, la movilización de líderes y lideresas por la lucha de sus derechos. Los derechos lingüísticos y sus luchas son esenciales para entender la distancia entre el ordenamiento jurídico y la realidad social de las comunidades indígenas, cuyo abandono estatal parece condenarlas más rápidamente a la extinción.

\subsection{Sujeto de derechos humanos}

Un gesto cotidiano como es tomar un bus se puede convertir en la acción detonante de cambios. Esa mujer negra que decidió un día cualquiera sentarse en un bus destinado para blancos generó reacciones dentro de una minoría oprimida, como fueron los negros en la época del apartheid en Estados unidos. Ella fue sujeto de derechos humanos con su impertinencia, desobediencia y desacato a una supuesta ley justa. Rosa no habló de leyes, fue su indignación reflejada en la narrativa del hecho mismo lo que resonó en la rebelión del pueblo negro.

El sujeto de derechos humanos no está reducido a un ser con un cúmulo de conocimientos legislativos o jurídicos, tampoco a un ser concienciado. Por el contrario, este es un ser que se reconoce no como medio sino como fin en sí mismo. Lo que hizo posible el "simple" gesto de esta mujer negra fue la identidad, la solidaridad, la capacidad de reflejarse en el otro o en los otros que sufrían la vergüenza, la humillación y la marginación; por mencionar lo menos grave de la época. Esto es lo que propicia un espíritu colectivo de lucha.

En las posibilidades de construcción de sujeto de derechos humanos en la reciente historia de violencia y barbarie en Colombia, se disciernen prácticas de rebelión y de reconocimiento entre sujetos de derechos humanos. Esa reciente historia que se caracteriza por un conflicto complejo, con varios actores armados prosistémicos como paramilitares insurgentes, 
narcotraficantes y militares. Por el otro lado están las guerrillas, y en el medio, la sociedad civil, las minorías.

En la historia de la construcción de Colombia en un Estado nación, al replicar modelos extranjeros que no aplicaban al contexto multicultural, multiétnico y plurilingüe, encontramos el primer gran tropiezo del país. No pensar un país desde su diversidad, sino buscando la uniformización. Se olvida que la democracia se construye desde la diferencia y que en el disenso se construyen propósitos comunes, pues las ganas de homogeneizar el pensamiento político han sido el principal causante de nuestra guerra.

Una de las poblaciones invisivilizada e ignorada después de la república es la población indígena. Es una de las minorías afectadas por un sistema opresor. Sin embargo, los indígenas han librado luchas con rebelión en busca de reivindicar sus derechos. Ellos han dicho: ¡vamos por lo nuestro, organicémonos, recuperemos nuestro territorio, nuestra identidad y el mayor representante de esta: nuestra lengua! La reivindicación central de los pueblos indígenas ha sido por el territorio. Este actor político aparece en el siglo XX en los años setenta, aún si sus luchas se remontan a la época de la conquista, su incidencia se hace visible desde Quintín Lame, el líder asesinado.

Defender su propia lengua implica para los pueblos indígenas reconocerse como sujetos activos de derechos, para propiciar de esta manera la reorganización de la comunidad desde individuos descolonizados, humanizados, ciudadanos de facto en acciones coherentes con las situaciones local-periféricas, convirtiéndose en actores que defiendan y reivindiquen su etnicidad, en especial su lengua, como portadora de unidad y alma de sus pueblos amenazados. Aunque los grupos étnicos son a menudo postergados, pueden, en la lucha por una distribución justa de los recursos, usar la etnicidad como un arma. La comunidad étnica funciona entonces como un movimiento social que crea la posibilidad de, por ejemplo, formular acciones políticas y económicas para darlas a conocer fuera de la comunidad.

\section{Derechos lingüísticos}

"La lengua es la base de nuestra identidad. Además, repasa las herramientas que tenemos a nuestra disposición para informar y ser informado" (Pueblo uw'a)

En la representación de la diversidad lingüística de la humanidad, existieron y existen lenguas dominantes. Podríamos llamarlas lenguas paternas. Este estatus ha estado ligado a las relaciones de poder, dominación, imperios, intereses económicos, opresión-oprimidos. Incluso entre poblaciones minoritarias, como los pueblos indígenas. Podríamos hacer una citación extensa de cómo se han impuesto en la historia ciertas lenguas a través de la violencia y el menoscabo a la dignidad humana de los pueblos, al lado de las resistencias que se propiciaron como reacción. No obstante, este trabajo no se concentra en una caracterización histórica del fenómeno.

En esa interacción de sociedades, las lenguas desfavorecidas han sido marginadas, silenciadas o han ido desapareciendo. Este flagelo sigue cobrando las voces de lenguas vivas cada vez con mayor velocidad. Desde que la sociedad agraria se reemplaza por la sociedad industrializada, la homogeneización prima en la transición para tecnificar y optimizar los procesos. Es a partir de la Revolución francesa cuando el ejercicio del poder del Estado nación convoca a la uniformidad. 
Si miramos las lenguas de poblaciones que históricamente han sido subordinadas, como es el caso de los pueblos indígenas frente al avasallamiento de la conquista del continente americano, encontramos que han desaparecido lenguas indígenas, pero también otras han sobrevivido o se han revitalizado.

Los derechos lingüísticos, que normalmente son clasificados como parte de los derechos económicos, sociales, culturales y ambientales (DESCA), pero que están innegablemente relacionados con derechos fundamentales y derechos civiles y políticos (DCP), se conocen también como derechos humanos minoritarios, colectivos o individuales.

En Colombia se han hecho estudios lingüísticos, sociolingüísticos y se ha estimulado la etnolingüística desde la universidad privada, como en la Universidad de los Andes, y desde instituciones como Caro y Cuervo. Sin embargo, esto no ha acompañado procesos de los hablantes, quienes son el centro de esta riqueza, patrimonio inmaterial.

No obstante, según Fernández (2000), hay tres principios básicos que inspiran el reconocimiento y la protección de los derechos lingüísticos, los cuales son: 1) libertad lingüística, derecho a la identidad lingüística. 2) Igualdad que posibilite la no discriminación a la diferencia. 3) Respeto al pluralismo.

Teniendo en cuenta la integralidad de los derechos humanos, y en su condición transversal, podemos dilucidar que los derechos lingüísticos se relacionan con el derecho a la educación intercultural bilingüe y diferencial, a la libre determinación, expresión y comunicación, al territorio, la justicia y reparación cultural, a la vida. Defender la lengua no para excluirse o marginarse en una postura etnocéntrica, sino para reafirmar su dignidad; reparación histórica a la limpieza étnica, a las campañas de evangelización de la Iglesia. La lengua hace parte fundamental de la dignidad humana, pues es lo más intrínseco, lo más nuestro, íntimo, a nuestra condición de seres humanos. Está llena de significados propios. La lucha por los derechos humanos es la defensa de la dignidad. Los derechos lingüísticos son una manifestación de la lucha por algo tan intrínseco y significativo al ser humano como lo es su lengua. La cooptación de tales derechos viola sistemáticamente otros derechos fundamentales.

La preocupación no es por la defensa cultural per se, sino por establecer las condiciones que permitan el goce de la esfera de igualdad limitada. Obligación que compete al Estado, pero los miembros del Estado evitan responsabilidades ligadas a las capacidades linguí́sticas. Es aquí donde la noción de derechos a la lengua instrumental juega su papel.

De esta manera, se entrevé la importancia de la palabra y de la escucha para poder responder a las diferentes realidades de los pueblos indígenas. La lengua emerge entonces como el principal medio de relación del presente con el pasado, para mirar hacia el futuro en una concepción del tiempo no lineal sino concéntrica, de permanente abrazo a quien nos da la vida: la Madre Tierra (Green, 2006).

La defensa de los idiomas tiene que ver con la defensa de los derechos humanos, la defensa de la dignidad de las personas, no solo de la indígena sino de la dignidad humana no indígena. El concepto "genocidio linguiístico", la "pérdida" o "muerte" de la lengua no pasa porque sí, no es natural o inevitable. Más bien, es situado social, cultural y políticamente 
dentro de un amplio nexo de relaciones de poder dentro y entre grupos lingüísticos (Skutnabb-Kangas, 1994).

Desde la visión de Stephen May (2011), la lengua mayoritaria es la lengua de mayor poder, prestigio, influencia o riqueza comunicativa, tiene influencia directa sobre la pérdida de la lengua, lo que no es solo, quizás ni siquiera principalmente, un problema lingüístico, sino que tiene que ver mucho más con poder, prejuicio, competencia (desigual) y en muchos casos, discriminación pública y subordinación.

Por supuesto, la pérdida y el cambio de una lengua siempre han ocurrido. Las lenguas se han levantado y caído, se han convertido en obsoletas, han muerto o se han adaptado a circunstancias de cambio con el objetivo de sobrevivir a lo largo del curso de la historia de la humanidad. Pero lo cualitativa y cuantitativamente diferente en el siglo XXI es el aumento sin precedente de este proceso de declinación y pérdida.

El reconocimiento de los derechos lingüísticos y la protección de las lenguas propician el amparo de los derechos fundamentales en su sentido más amplio, y previenen la aparición de conflictos, internos e internacionales, haciendo frente a una de las causas más expresivas de su surgimiento (Fernández, 2000). Aquí vislumbramos el deber ser o el nivel valórico que defiende la pluralidad de la humanidad y expresa una armonía ideal.

\section{Marco legal de los derechos lingüísticos}

En cuanto a lo jurídico, se cuenta con una lista amplia de instrumentos del derecho internacional humanitario ratificados por Colombia y leyes nacionales, como insumos en la defensa y reivindicación de los derechos lingüísticos. Aunque el sujeto de derechos humanos no está reducido a un ser con un cúmulo de conocimientos legislativos o jurídicos, estos insumos brindan la posibilidad de empoderar la lucha colectiva o individual por los derechos. $\mathrm{Si}$ bien es cierto que los derechos lingüísticos se enmarcan en su mayoría como una especificidad de los derechos económicos, sociales, culturales y ambientales (DESCA), encontramos que el Pacto Internacional de Derechos Civiles y Políticos, adoptado por la Asamblea General de las Naciones Unidas de 16 de diciembre de 1966 y ratificado por Colombia, contiene los artículos 13, 14 y 27, que soportan jurídicamente las luchas de los pueblos y la exigibilidad de sus derechos.

Otro instrumento relevante en la esfera internacional que favorece los derechos de los pueblos indígenas es el Convenio 169 de la OIT (artículos 2 y 4 ).

Se cuenta también con la Convención sobre los Derechos del Niño, que, de conformidad con el artículo 49, comenzó a regir desde el 2 de septiembre de 1990. El artículo 30 se refiere al tema lingüístico.

Existe un instrumento no ratificado y que no vincula ni obliga a Colombia a cumplir estos derechos. Es la Declaración Universal de los Derechos Lingüísticos de 1996, hecha en Barcelona. Una propuesta que logra recopilar firmas de lingüistas tales como Noam Chomsky y personalidades reconocidas por su labor humanitaria o influencia en las resistencias o cambios sociales, como Nelson Mandela, entre otros. A pesar de su nula incidencia jurídica, la ONG Linguapax que propuso esta iniciativa se dedica a la valoración y protección de la diversidad lingüística mundial. Su trabajo va en dirección de los procesos autónomos y locales. 
La legislación colombiana que da aplicación a normas internacionales en la materia de protección de las lenguas indígenas es la siguiente:

- Ley 74, de diciembre 26 de 1968, aprobatoria del Pacto Internacional de Derechos Civiles y Políticos de 1966. Mediante esta Ley, Colombia asumió el compromiso de acatar lo establecido en el PIDCP. Por lo tanto, el artículo 27 que protege las lenguas indígenas es vinculante.

- Ley 12, de enero 22 de 1991, aprobatoria de la Convención sobre Derechos del Niño, de 1989, en la cual el Estado colombiano se compromete en el artículo 30.

- Ley 21, de marzo 4 de 1991, aprobatoria del Convenio 169 de la OIT sobre pueblos indígenas y tribales en países independientes. Convenio que obliga, bajo el artículo 28, a respetar las garantías relacionadas con la cultura, la lengua y el rol del Estado en estas.

- Ley 1037, de 25 de julio de 2006, aprobatoria de la Convención para Salvaguardar el Patrimonio Cultural Inmaterial.

Artículo 10. El castellano es el idioma oficial de Colombia. Las lenguas y dialectos de los grupos étnicos son también oficiales en sus territorios. La enseñanza que se imparta en las comunidades con tradiciones lingüísticas propias será bilingüe.

Artículo 19. Se garantiza la libertad de cultos. Toda persona tiene derecho a profesar libremente su religión y a difundirla en forma individual o colectiva. Todas las confesiones religiosas e iglesias son igualmente libres ante la ley.

- Ley de Lenguas 1381 de 2010. Aparece en un contexto donde urge la necesidad de salvaguardar el patrimonio inmaterial que son las lenguas, pero más importante aún la pervivencia de los pueblos que las hablan. Es una ley que fue creada de una manera participativa e incluyente, es decir, convocó líderes y lideresas del movimiento indígena para su construcción. Sin embargo, esta ley parece haber sido poco socializada entre los pueblos indígenas o las metodologías de socialización no presentan un enfoque étnico que tenga en cuenta la lengua propia. De esta manera, el desconocimiento del español se convierte en un factor limitante o excluyente. Ese desconocimiento margina y perpetúa la exclusión, pese a que Colombia se declara en la Constitución de 1991 como un Estado de derecho pluralista y multicultural.

En refuerzo a esta ley encontramos unas sentencias de tutela de la Corte Constitucional, que defienden los derechos de los indígenas consagrados en la Constitución, entre las que podemos mencionar las siguientes: T-1105/08 y T-116/11. En las cuales se otorga por ejemplo "especial garantía al reconocimiento, igualdad de condiciones de todas las etnias y culturas habitantes en Colombia".

Colombia cuenta con un insumo de leyes, participación en tratados o acuerdos internacionales vinculantes y la Constitución de 1991, que favorecen a los pueblos indígenas enormemente, es decir, podríamos decir que hay una legislación garantista. Aun así, la realidad de los pueblos indígenas en sus territorios es contradictoria con esta normativa. Un ejemplo de las consecuencias de esta contradicción es el exterminio de los pueblos indígenas 
física o culturalmente con una enorme velocidad, situación que parece imparable (Organización Nacional Indígena de Colombia -ONIC-, 2013). No obstante, lo que ha permitido la protección de la pervivencia de los pueblos ha sido el empoderamiento de las luchas propias, la revitalización de su lengua y cultura, además de la movilización en la emancipación de los pueblos para lograr el cumplimiento del goce de sus derechos.

La Ley de Origen, según los pueblos indígenas, deriva del orden de la naturaleza y el cosmos, es todo aquello que rige la vida; es el principio espiritual de la existencia que legisla todo en armonía. Los principios de la ley de origen son: espiritualidad, orden, equilibrio, pagamento, respeto, territorio, valoración de lo nuestro, y se fundamenta en el conocimiento heredado por generaciones de indígenas de la Sierra a lo largo del tiempo. El pensamiento, el consejo, la oralidad son elementos centrales para la Ley.

Esta Ley y el derecho infraestatal o de las minorías son de tradición oral de sociedades "ágrafas"; este derecho es considerado sin orden, valores o norma, frente al derecho estatal u occidental, el cual es escrito, hegemónico y legitimado social, académica, jurídica y políticamente. Pero esta afirmación es contradictoria, pues una sociedad conformada tiene intrínsecamente unos sistemas de valores y de normas. Lo que diferencia a una sociedad de otra es su concepción del conflicto, lo cual va a influir en el significado, las normas y los procedimientos para prevenir, transformar o resolver los conflictos.

Múltiples sistemas de derecho coexisten con el derecho estatal y son directamente proporcionales a la diversidad cultural. La multiplicidad y variedad aún persisten, a pesar de que la diversidad jurídica es silenciada y no es visibilizada. En el ámbito internacional solo se reconocen 170 países en el sistema interestatal de derecho, pero si se tuvieran en cuenta criterios antropológicos y lingüísticos serían cerca de ocho mil.

Los pueblos indígenas de Colombia poseen cinco sistemas múltiples de solución de conflictos: 1. El segmentario. 2. El de autoridades comunales permanentes. 3. El religioso. 4. El de compensación directa. 5. El de sustitución y complementación. Los hombres y mujeres líderes indígenas lograron en 1991, durante la Asamblea Nacional Constituyente, la transformación en la concepción de una sociedad uniformada de una sola lengua, una ley única y una única religión, a una sociedad plural. Es a partir de la Constitución del 91 que se enuncian y reconocen los pueblos indígenas y sus derechos desde la visión de multiculturalidad.

Hay que conocer cultural y antropológicamente los derechos indígenas sin separarlos, pues estos tienen una concepción holística, que da cuenta del sistema cultural-jurídico que regula la vida social, que consagra derechos y deberes entre sí y con la naturaleza, que previene, transforma y soluciona los conflictos, haciendo posible la reproducción y la convivencia social. Así, la esencia que diferencia el derecho indígena del derecho estatal es la no separación de las normas culturales y jurídicas y su oralidad.

\section{Justicia transicional y derechos lingüísticos para indígenas}

Partiendo del presupuesto de que la paz no es solamente ausencia de guerra armada, hablamos de la violencia estructural que se perpetúa silenciosamente. Esta sección se concentra en el movimiento indígena frente a la paz, teniendo en cuenta el riesgo de 
exterminio físico y cultural de los pueblos indígenas ocasionado por el conflicto armado y la exclusión que históricamente los ha victimizado.

Proponemos el concepto de justicia transicional, entendida como un proceso de transformación política y social que equilibra la justicia y la paz para proteger y cumplir los derechos humanos y ejercer la democracia. La fundamentación para este concepto es el principio de una paz estable y duradera, que necesita unos acuerdos básicos como punto de partida y pretende que el uso del concepto de derechos humanos con su carácter integral y transversal cubra la justicia restaurativa y trascienda la justicia retributiva o punitiva. Por lo tanto, una justicia transicional que no sea omnicomprensiva de los diferentes aspectos, significa la parcialización del goce efectivo de derechos humanos, lo que no sería suficiente para hablar de un verdadero cambio, pues se quiebra ese equilibrio que sostiene un derecho con el otro. Sin ese goce pleno no se responde a los principios de un Estado de derecho, sino que se rompe la confianza de los ciudadanos al negar la reivindicación de los derechos de las víctimas y, por ende, se coarta la verdadera transformación social en condiciones de igualdad en la pluralidad.

El aspecto cultural manifiesta afectaciones difíciles de identificar, sin embargo tiene un valor fundamental en la restauración integral, pues aborda conceptos identitarios, valores propios, espiritualidad, lengua, desarraigo y afectaciones sicológicas. Lo anterior exige una adecuación institucional para la revitalización de las prácticas culturales.

Los ecos de las voces de las lenguas nativas que han desaparecido nos dejan su enseñanza, su memoria para la no repetición, el cuidado, la lucha y la defensa. Las voces que sí han podido ser escuchadas siguen resonando. Esas voces, a veces ya sin lengua propia, pero tal vez con la lengua dominante, han reivindicado sus derechos. Otras, que conservan su lengua nativa pero no han podido luchar, siguen en el silencio del olvido y están desapareciendo.

\section{Conclusiones}

Las categorías occidentales de derecho, derechos humanos y derecho lingüístico, difieren de la concepción de los pueblos indígenas de Colombia. Es decir, en lengua propia no existen esos términos o una traducción equivalente. Esos conceptos se han ido aprendiendo y se han incluido en su discurso poco a poco.

La vitalidad lingüística no es a priori fortaleza política-organizativa. Esa fuerza identitaria no garantiza la pervivencia, como lo evidencia la ONIC, donde el desplazamiento y el confinamiento están extinguiendo pueblos. Es decir, la identidad de un pueblo no garantiza la emancipación y la lucha por los derechos humanos, pero el discurso de los derechos humanos y lingüísticos puede empoderar las luchas por el territorio y por la dignidad.

Los derechos humanos necesitan movimiento, accionar para poder existir; sin esos sujetos que exigen, estos se convierte en mera ideología, inconsciencia. Todos los logros jurídicos han sido posibles por las vías de hecho en acción del movimiento indígena. La aplicación de tales leyes o políticas es parcializada; en otras palabras, estas han sido mal aplicadas. Los procesos que sobresalen han sido iniciativas propias, en demanda del apoyo estatal.

Los derechos humanos, al ser integrales, tienen una relación intrínseca con los derechos lingüísticos, pues son interdependientes. Esa integralidad de los derechos humanos hace 
inevitable la interrelación de ambos. Si no hay goce de los derechos lingüísticos, automáticamente no hay goce de derechos humanos.

La realidad de los pueblos indígenas en sus territorios es contradictoria con la amplia normativa que existe en los ámbitos nacional e internacional. La solución a esta falta de garantías de sus derechos humanos y lingüísticos ha sido el empoderamiento de las luchas, la revitalización de su lengua y cultura, y además, la movilización en la emancipación de los pueblos para lograr el cumplimiento del goce de sus derechos. Aunque la lengua nativa es parte esencial al definir a un pueblo indígena, por situaciones históricas no todos los pueblos han conservado su lengua, aun así deben ejercer su derecho a defenderla.

\section{Referencias}

Angarita, C. E. (2000). Estado, poder y derechos humanos en Colombia. Bogotá: Códice.

Bauman Z. (1999). Modernidad líquida. Buenos Aires: Fondo de Cultura Económica.

Congreso de la República de Colombia. (1968). Ley 74, de diciembre 26 de 1968, aprobatoria del Pacto Internacional de Derechos Civiles y Políticos de 1966. Bogotá: Imprenta Nacional.

Congreso de la República de Colombia. (1991). Ley 12, de enero 22 de 1991, aprobatoria de la Convención sobre Derechos del Niño de 1989. Bogotá: Imprenta Nacional.

Congreso de la República de Colombia. (1991). Ley 21, de marzo 4 de 1991, aprobatoria del Convenio 169 de la OIT sobre pueblos indígenas y tribales en países independientes. Bogotá: Imprenta Nacional.

Congreso de la República de Colombia. (2006). Ley 1037, de 25 de julio de 2006, aprobatoria de la Convención para Salvaguardar el Patrimonio Cultural Inmaterial. Bogotá: Imprenta Nacional.

Congreso de la República de Colombia. (2010). Ley 1381 de 2010, Ley de Lenguas. Bogotá: Imprenta Nacional.

Corte Constitucional colombiana. (2008, 6 de nov.). Sentencia T-1105/08. M.P. Humberto Antonio Sierra Porto.

Corte Constitucional colombiana. (2013, 11 de dic.). Sentencia T-116/12. M.P. Humberto Antonio Sierra Porto.

Fernández, C. R. (2000). Marco jurídico internacional de los derechos lingüísticos. Madrid: Universidad Carlos III de Madrid.

Green, A. (2006). La educación desde la Madre Tierra: un compromiso con la humanidad. Artículo del proyecto de investigación: "La lucha de los siete hermanos y su hermana Olowaili en defensa de la Madre Tierra: hacia la pervivencia cultural del pueblo Tule". file://C:/Documents\%20and\%20Settings/Administrador/Mis\%20documentos/Downl oads/6646-18520-2-PB.pdf 
Gröll, I., Montes, M.E. \& Pappenheim, R. (2009). Las lenguas autóctonas en Colombia: consideraciones alrededor de su legitimación en la Constitución de 1991. En D. Aguirre (comp.). Bogotá. Universidad de los Andes.

Linguapax. (1996). Declaración Universal de los Derechos Lingüísticos. Barcelona. Recuperado de http://www.egt.ie/udhr/udlr-es.html

Lovich, V. (2010). Educación intercultural bilingüe (EIB), una visión comparada entre Ecuador y Bolivia, 2001-2006. (Tesis de pregrado). Universidad Externado de Colombia. Bogotá.

Maquieira V. (2006). Mujeres, globalización y derechos humanos. Madrid: Cátedra.

May, S. (2011). Language and Minority Rights: Ethnicity, Nationalism and the Politics of Language. New York: Routledge.

Organización de las Naciones Unidas. (16 de diciembre de 1966). Pacto Internacional de Derechos Civiles y Políticos. Recuperado de http://www.Cinu.org.mx/onu /documentos/ pidcp.htm

Organización de las Naciones Unidas. (1989). Convención sobre los Derechos del Niño.

Organización Internacional del Trabajo -OIT-. (1989). Convenio 169 de la OIT, sobre pueblos indígenas y tribales.

Organización Nacional Indígena de Colombia -ONIC- (2013). Comunicados ONIC. Recuperado de www.onic.org.co

Pavón, M. (1995). La recuperación de lenguas nativas como búsqueda de la identidad étnica. Bogotá: Universidad de los Andes.

Pineda, R. (2000). El derecho a la lengua: una historia de la política lingüística en Colombia. Bogotá: Universidad de los Andes.

Restrepo, M. H. (2006). Teoría de los derechos humanos y políticas públicas o de las tensiones entre derechos humanos y mercado. Tunja: Editorial UPTC.

Rojas, C. M. (2013). La diversidad lingüística en Colombia: protección jurídica de las lenguas indígenas. Revista Pensamiento Jurídico, (22).

Skutnabb-Kangas, T. \& Phillipson, R. (1994). Linguistic Human Rights, Past and Present. New York: Mouton de Gruyter.

\section{Derechos de autor}

Los derechos de autor de este artículo son retenidos por los autores, con los derechos de primera publicación otorgados a la revista. Este es un artículo de acceso abierto distribuido bajo los términos y condiciones de la licencia Creative Commons: Reconocimiento-NoComercial-CompartirIgual 4.0 Internacional

Derecho real 